\title{
Effectiveness of a single-tuft toothbrush for control of newly formed dental biofilm
}

\author{
lohana Hasegawa', Camila Veríssimo', Victor Angelo Montalli', Marcelo Sperandio', Daiane Cristina Peruzzo ${ }^{1}$ \\ 'São Leopoldo Mandic - SLMANDIC, São Leopoldo Mandic Dental School and Research Institute, Department of Oral Pathology, Campinas, SP, Brazil
}

\begin{abstract}
Aim: To compare the effectiveness of a single-tuft toothbrush (STB) with conventional toothbrushes (CT) to control dental biofilm neoformation in the dentogingival area. Methods: For this cross-sectional prospective blind study, 20 periodontally healthy subjects were selected and randomly divided into 4 groups: STB; CT; CHX - chlorhexidine mouthwash (positive control) and PS - placebo mouthwash (negative control). The subjects were instructed to use only the assigned care method for $72 \mathrm{~h}$ with a 7-day washout period between experiments. The evaluated parameters were visible and disclosed plaque indices (PI and DPI), gingival bleeding index (GBI) at baseline (T-0) and at the end of each experimental period (T-72). Results: Data analysis demonstrated that at T-0 no difference was observed for any of the parameters ( $p>0.05$ ); after $72 \mathrm{~h}, \mathrm{CT}$, STB and $\mathrm{CHX}$ showed equivalent effectiveness at controlling biofilm. When the PI data were analyzed, between T-0 and T-72, STB was similar to $\mathrm{CT}$ and $\mathrm{CHX}(\mathrm{p}<0.05)$, whereas for DPI, STB was significantly superior to the other methods. Except for PS, all methods yielded similar results for $\mathrm{GBI}(\mathrm{p}<0.05)$. Conclusions: The tested STB was effective at controlling short-term dental biofilm neoformation on the dentogingival area.
\end{abstract}

Keywords: Dental Plaque. Biofilms. Oral Hygiene.

\section{Introduction}

Gingivitis is primarily caused by dental biofilm, which must be controlled in order to achieve and maintain periodontal health ${ }^{1}$. The bacteria in biofilm are mostly in balance with the host, which denotes a state of persistent periodontal health. When such homeostasis is broken due to inadequate oral hygiene, gingivitis settles in, which may progress into periodontitis ${ }^{2}$. From the pathophysiological viewpoint, no individual is immune to gingivitis, provided biofilm is allowed to accumulate over time, breaking the gingival homeostasis.

When intrasulcular homeostasis is broken, visible clinical changes begin to emerge, such as spontaneous gingival bleeding, bleeding on brushing, erythema, swelling and changes in gingival texture ${ }^{2,3}$. It is therefore paramount to concentrate efforts at tackling the root of the problem using methods of oral hygiene and consequently halting dental biofilm formation ${ }^{4}$. The gold standard for prevention of gingivitis is mechanical removal of biofilm by regular toothbrushing ${ }^{4-6}$. For hygiene to be performed according to the

Received for publication: July 19, 2016 Accepted: November 16, 2016

Correspondence to: Daiane C. Peruzzo

São Leopoldo Mandic Institute and Research Center Rua José Rocha Junqueira 13, Ponte Preta, CEP: 13045-755 - Campinas SP Brasil Phone: +55 1932113659 - Fax: +55 1932113635 E-mail: daiaperuzzo@yahoo.com.br instructions by dental professionals, biofilm control strategies must be tailored to the needs of each individual.

Toothbrush and toothpaste are undoubtedly the most widespread tools for mechanical removal of plaque and debris from the tooth surface. Thus, to meet specific individual needs several devices were developed, for instance, interdental brushes and dental floss for interdental areas, and single-tuft brushes, for intra-sulcular and even buccal/lingual/palatal areas ${ }^{7-10}$.

In normal circumstances, teeth cleaning solely with a conventional toothbrush will not remove biofilm equally from all surfaces ${ }^{11}$. Complementation is therefore 
required using auxiliary devices, such as dental floss or tape, interproximal brushes and/or single-tuft brushes, according to the shape, size and access to the cleaned site. Single-tuft brushes are delicate and may be advised for specific areas. Usually, they are recommended for difficult to access sites, such as furcations, distal surfaces of molars, areas of amputated roots, buccal or lingual surfaces with irregular gingival margin, crowded areas and proximal surfaces of isolated teeth ${ }^{12}$. Additionally, because it is relatively uncomplicated to direct STB towards the gingival sulcus, they may be the most effective method to remove biofilm from deep pockets.

The flowchart of evidence on the role of supragingival bacterial biofilm is complete when biofilm control leads to gingival health ${ }^{1}$. Evidence derived from large cohort studies have demonstrated that high standards of oral hygiene will ensure stability of the periodontium ${ }^{13}$. Both short-term and long-term cross-sectional as well as longitudinal studies have shown that the incidence of gingivitis and biofilm accumulation still seems to be high even among the adult population that brush their teeth frequently ${ }^{14}$.

Despite STB being highly recommended by periodontal specialists, there are few studies ${ }^{15-17}$ demonstrating the effectiveness of such tools at controlling dental biofilm at crevicular sites. The aim of this study was to compare the effectiveness of single-tuft brushes against the gold standard, namely conventional toothbrushes, at controlling newly formed biofilm at the dentogingival area of healthy individuals.

\section{Material and methods}

\section{Sample selection}

This study was approved by the Ethics Committee of the São Leopoldo Mandic Dental School, Campinas / SP, protocol \#356827/2013. Sample size was based on previously published studies of similar design ${ }^{18,19}$ and consisted of 20 dental students from the São Leopoldo Mandic Dental School.

The inclusion criteria were: systemically and periodontally healthy subjects (probing depth $\leq 3 \mathrm{~mm}$ and no gingival bleeding) ${ }^{20-21}$, aged between 18 and 30 years with a minimum of 20 remaining teeth, who agreed to participate in the study. Exclusion criteria were: presence of cervical restorations, antimicrobial therapy for any medical or dental condition within 6 months prior to the trial, use of drugs known to affect the periodontal environment (anti-inflammatories, pain-killers, contraceptives, anticonvulsants, immunosuppressants, cyclosporin, anticoagulants and calcium channel blockers) also within 6 months prior to the baseline periodontal examination, orthodontic treatment or devices, pregnant women and breastfeeding mothers.

\section{Study design}

Two types of toothbrushes were compared: a single-tuft brush (Bitufo ${ }^{\circledR}$ - Hypermarcas, Senador Canedo - GO, Brazil) and a conventional toothbrush (Bitufo ${ }^{\circledR}$ - Hypermarcas, Senador Canedo - GO, Brazil). 0.12\% chlorhexidine mouthwash (Bitufo®,
Senador Canedo - GO, Brazil) was used every $12 \mathrm{~h}$ as a positive control, whereas a placebo solution (Bitufo $\AA$ - Hypermarcas, Senador Canedo - GO, Brazil) with similar features as the chlorhexidine mouthwash, but without the active ingredient, was used as a negative control. The groups were defined as follows: STB - single-tuft brushes (test), $\mathrm{n}=20$; CT - conventional toothbrush (gold standard), $\mathrm{n}=20$; CHX - chlorhexidine mouthwash $(0.12 \%$ - positive control $), n=20$; and PS - placebo solution (negative control), $\mathrm{n}=20$. During each experimental phase, the subjects were instructed to use solely the method designated to their group, excluding any other additional cleaning strategy. Each experimental phase lasted $72 \mathrm{~h}$ with a 7-day washout period in between, in order to avoid a possible residual (carryover) effect of the previous treatment method. During this washout period, all volunteers used a standard toothbrush and toothpaste provided by the researchers.

The mouthwash solutions were packed and coded in order to prevent identification of the used product. The codes were revealed only when the study was complete.

\section{Clinical Experimental Phase}

Following patient selection, a clinical oral examination was performed by a single examiner (IH), trained and calibrated to obtain the following initial clinical parameters: visible plaque index (PI), disclosed plaque index (DPI) and gingival bleeding index $(\mathrm{GBI})$, according to Ainamo and $\mathrm{Bay}^{22}$, as shown in Figure 1 (A, B and $\mathrm{C}$, respectively). In addition, periodontal evaluation was performed, which included probing depth (PD), gingival recession and clinical attachment level, in order to assure absence of gingivitis clinically. Subsequently, professional biofilm removal was performed on each volunteer using a rubber cup and prophylaxis paste. Personalized instructions for toothbrushing were given individually and verbally by another researcher (CV), according to brush (conventional and STB) and solution (placebo and chlorhexidine). Only during the washout period were the subjects encouraged to apply other conventional oral hygiene methods, such as dental floss or tape.

Following the trial phase, a second professional prophylaxis session was performed. The volunteers were then randomly assigned (using a computer list) to their respective sequence of oral hygiene methods, observing the 7-day washout period ${ }^{20}$. PI, DPI and GBI were recorded both at the beginning and at the end of each trial period.

\section{Statistical Analysis}

Only the subjects who completed the study $(n=18)$ were considered for statistical purposes. Prior to the analysis, the Kolmogorov-Smirnov test was applied to assess normality. For intra-group analysis (between periods) of the data (PI, DPI and GBI), Student's t test was used. For inter-group analysis (between treatments), ANOVA/Tukey tests were applied. BioEstat 5.0 (Sustainable Mamirauá Institute, Belém, PA, Brazil) software was used for statistical calculations. For all analyzes, the significance level was set at $5 \%$. 

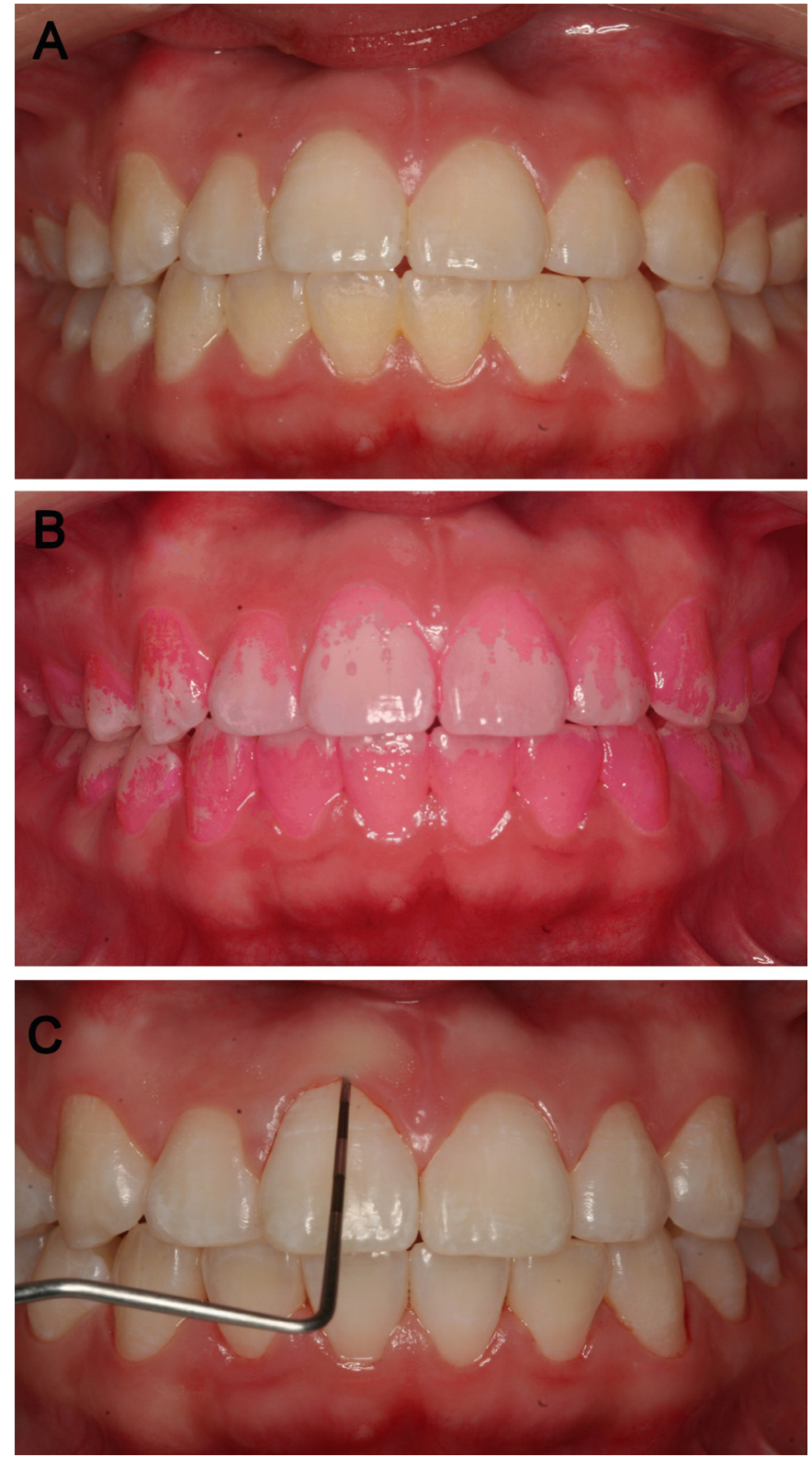

Fig.1. Intra-oral examination for the following clinical parameters: (A) visible Plaque Index (PI); (B) Disclosed Plaque Index (DPI), and (C) Gingival Bleeding Index (GBI).

\section{Results}

Twenty volunteers were selected from March to June 2013. The participants were aged between 18 and 30 years (mean age 21.1 years), 13 females and 7 males. Among the 20 initially selected individuals , 18 completed the study and two were lost to follow-up.

Intergroup analysis at the early experimental stage (T-0) revealed no statistically significant difference between treatments (STB, CT, CHX, PS) for any of the evaluated parameters (PI, DPI, GBI), demonstrating homogeneity between the groups (Figure 2A). After $72 \mathrm{~h}(\mathrm{~T}-72)$ (Figure 2B), a significant difference was observed $(p<0.05)$ only for PS in terms of PI and DPI, but not GBI.

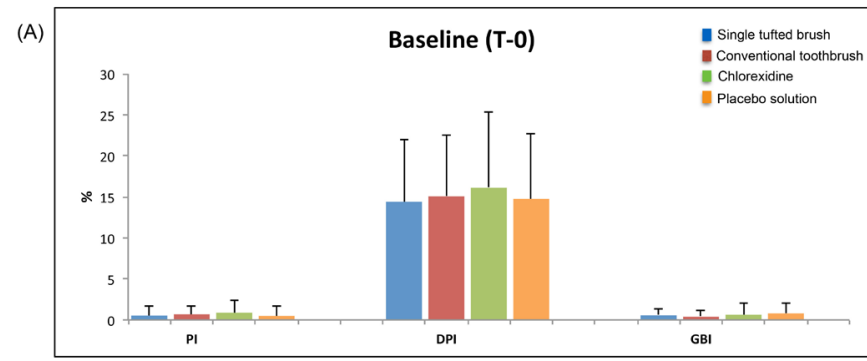

(B)

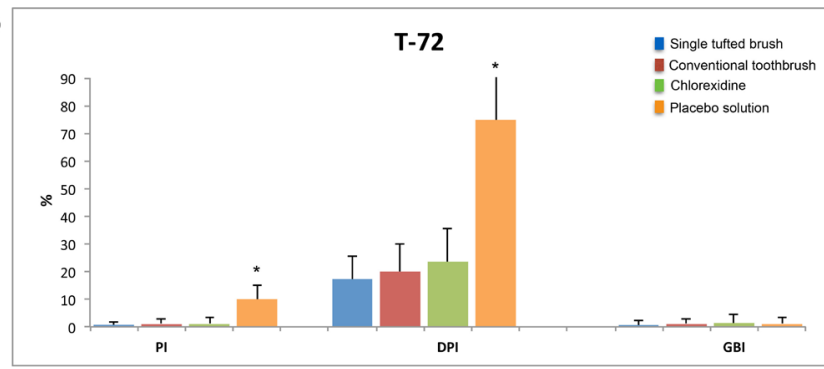

Fig.2. Mean $( \pm S D)$ for the clinical parameters at baseline $(T-0)(A)$, and after $72 \mathrm{~h}(B)$ for single-tuft brush (STB), conventional toothbrush (CT), chlorhexidine (CHX) and placebo solution (SP).

* indicate significant intragroup differences for the clinical parameters evaluated, by Anova and Tukey test $(p<0.05)$.

In the intra-group comparison between $\mathrm{T}-0$ and $\mathrm{T}-72$, the percentage of accumulated visible plaque (PI) (Figure 3) increased significantly only in the PS group $(\mathrm{p}<0.05)$. As shown in Figure 4, assessing the percentage of disclosed plaque (DPI), a significant difference was observed in CT, CHX and PS, while the STB group showed similar results between T- 0 and T-72 $(\mathrm{p}<0.005)$.

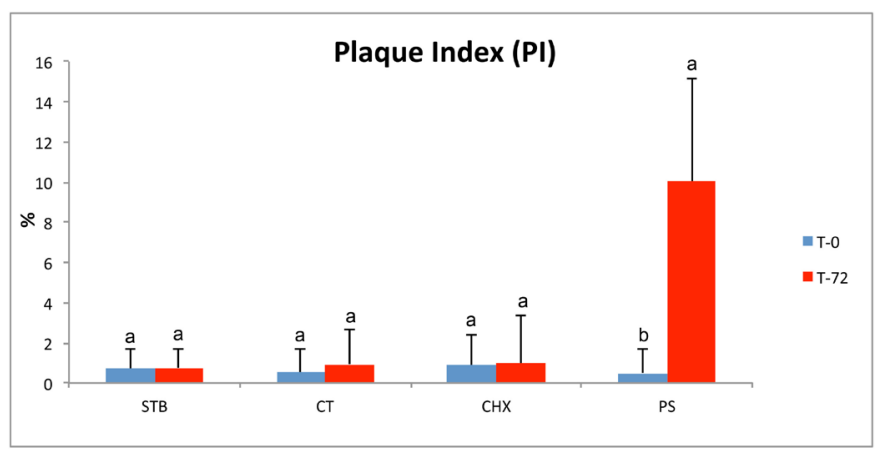

Fig.3. Mean $( \pm \mathrm{SD}$ ) for visible Plaque Index (PI), for the treatments, at baseline $(\mathrm{T}-0)$ and after $72 \mathrm{~h}$ (T-72) to single-tuft brush (STB), conventional toothbrush (CT), chlorhexidine (CHX) and placebo solution (SP).

Different lowercase letters indicate significant intragroup differences over time, by Student t test $(p<0.05)$.

Regarding GBI (Figure 5), no significant differences were observed between T-0 and T-72 for all treatments. 


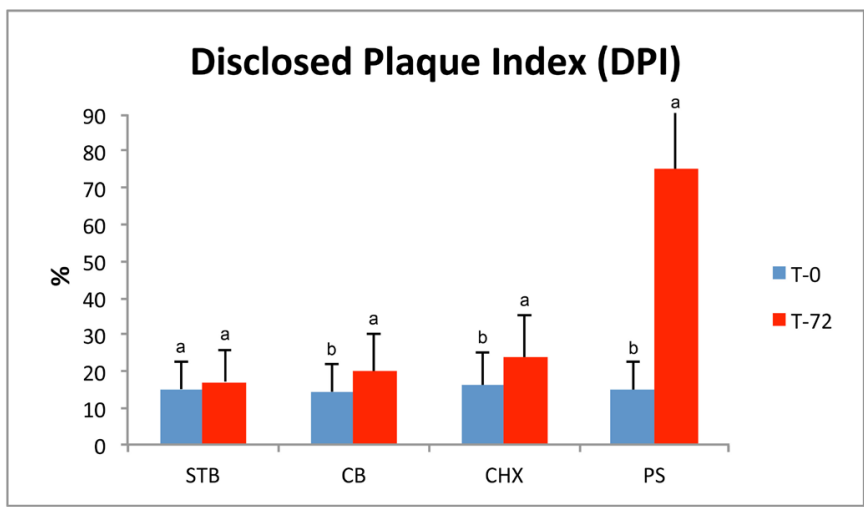

Fig.4. Mean ( \pm SD) Disclosed Plaque Index (DPI) for the treatments at baseline (T-0) and after $72 \mathrm{~h}$ (T-72) for single-tuft brush (STB), conventional toothbrush (CT), chlorhexidine (CHX) and placebo solution (SP).

Different lowercase letters indicate significant intragroup differences over time, by Student $t$ test $(p<0.05)$.

\section{Gingival Bleeding Index (GBI)}

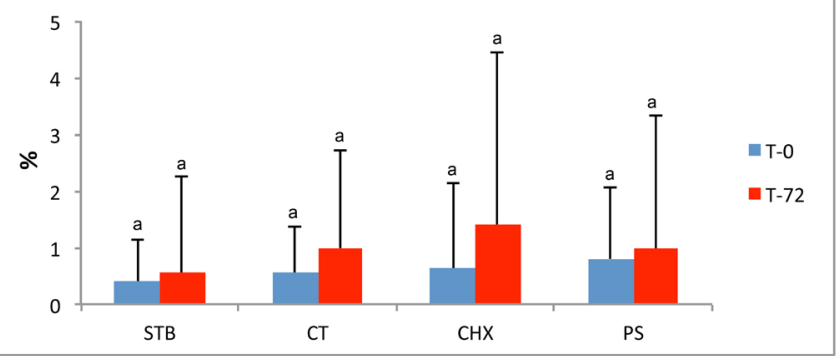

Fig.5. Mean $( \pm S D)$ Gingival Bleeding Scores (DPI) for the treatments at baseline (T-0) and after $72 \mathrm{~h}$ (T-72) to single-tuft brush (STB), conventional toothbrush (CT), chlorexidine (CHX) and placebo solution (SP).

Different lowercase letters indicate significant intragroup differences over time, by Student t test $(p<0.05)$.

\section{Discussion}

Faced with the limitations of conventional hygiene methods, new types of brushes have been developed, including electric toothbrushes, single-tuft and interdental brushes ${ }^{7,8,23}$. Tooth brushing per se is often insufficient to remove dental biofilm, particularly from interproximal and dentogingival areas. In turn, such scenario will demand complementary strategies to tackle biofilm disruption, including the use of dental floss/tape, interdental brushes, mouthwashes, etc. Only a handful of methodologically sound studies have focused on the effectiveness of such methods, especially in the intra-sulcular area. In this context, the present cross-sectional and prospective study aimed to evaluate the effectiveness of single-tuft brushes to control the new formation of bacterial biofilm at this particular site.

The methodological design of the present study allowed for testing all volunteers for all evaluated methods, thus reducing possible biases. Additionally, the inclusion of washout periods minimized the residual effects of the methods used before each new treatment ${ }^{24-26}$. Such study design may counterbalance carryover interferences and provide an estimate of treatment effect with minimal increase in variance, even if carryover is included in the model.

At baseline (T-0), no difference was observed between treatments for any of the parameters evaluated, demonstrating sample homogeneity between groups. At T-72, however, differences were observed in the placebo group for PI, DPI, but not for the GBI. These results reflect the relatively low hygiene withdrawal period in this sample of periodontally healthy individuals. At $72 \mathrm{~h}$, no clinically evident signs of gingival inflammation could be detected $33^{27}$, corroborated in the present study by the GBI values.

Additionally, scanning electron microscopy studies evaluating the initial stages of supragingival plaque formation confirmed the presence of a microbial deposit-free zone located between the biofilm layer and the gingival margin ${ }^{28}$. Bergström ${ }^{29}$ and Quirynen and coworkers ${ }^{30}$, when analyzing the initial stages of biofilm formation by sequential photographic records registered clinically this event. In their study, the biofilm-free zone was not stained by plaque-disclosing solutions. Subsequently, studies have shown that a supragingival plaque-free zone persists for up to $96 \mathrm{~h}^{31,32}$.

In this study, both disclosed and visible plaque indices were used to assess plaque scores and biofilm new formation. Visible plaque index (PI) was used to demonstrate gross plaque accumulation, whereas DPI was used to detect low amounts of plaque, as it is a much more sensitive method than PI. Although the use of disclosing solutions in the management of biofilm control can be somehow discouraging for some patients, when combined with index scales, they enable comparisons between new and existing oral hygiene products ${ }^{33}$. The choice for disclosing tablets over disclosing solutions was based on the fact that the former is widely used and is likely to be less disturbing of the biofilm, since the latter involves mechanical application of the solution with a cotton swab, which in turn may disrupt biofilm and risk false negatives ${ }^{34}$.

When confronting the results between T-0 and T-72, only the placebo solution showed a significant difference to PI. It is important to stress again that this index requires a greater accumulation of biofilm on the tooth surface for clinical detection. As for DPI, greater biofilm accumulation for the conventional brush, placebo solution and chlorhexidine solution groups was present, which was not observed in the group that used the singletuft brush. This may reflect the macrostructural characteristics of the single-tuft brush, which has a small head with bristles directed towards the area to be cleaned and must necessarily be used on a single surface of the tooth at a time, thus resulting in thorough, slower and more rational brushing. These findings agree with those by Ferraz et al. ${ }^{15}$, who compared mechanical biofilm control with conventional and single-tuft brushes and concluded that the singletuft brush group had a lower PI than the conventional brush groups after a 4-week period. The results obtained in the study by Lee and Moon26, which evaluated the effectiveness of single-tuft brushes on the buccal and lingual surfaces of molars also corroborate the findings of the present study. They concluded that difficult access areas could be best reached using this type of brush.

In the present study, chlorhexidine was used as a positive control, as it is independent from an individual's manual 
dexterity and is regarded as a gold standard for chemical plaque control due to its bactericidal and bacteriostatic properties ${ }^{35-37}$. A concentration of $0.12 \%$ was selected based on a previous study ${ }^{38}$, which demonstrated that a lower concentration of $\mathrm{CHX}$ was just as effective at reducing gingivitis as the traditional $0.20 \%$. Rinsing is easier than either brushing or flossing and takes less time, therefore requiring a shorter attention span. Patients also tend to be more concerned with a "fresh breath" than with plaque and gingivitis levels; consequently, patient adherence to rinsing may be higher in this case than to adequate brushing and flossing (or other cleaning dispositive) $)^{39}$.

Rapp and coworkers ${ }^{16}$ compared the Bass technique (conventional brushes) using single-tuft brushes alone or in combination with dental flossing in interproximal areas. Their results showed that, histomorphometrically, the Bass technique and the combination of single-tuft brushes with floss yielded very similar results and slightly better than the Bass-floss combination, while the use of single-tuft brushes without dental flossing showed poorer results. The findings from Rapp et al. ${ }^{16}$ do not corroborate those from the present study. It is important to highlight that their analysis involved a histomorphometric evaluation of biopsies from interproximal areas after 28 days. Such different methodological approaches are not directly comparable and any loose parallels can only be established based on extrapolation.

Franceschi and Oppeman ${ }^{17}$ evaluated the interproximal cleaning capacity of dental flossing and toothpicking with that of a single-tuft brush and found that both were able to maintain adequate levels of hygiene and gingival health. Under special circumstances, whenever the use of dental floss is not applicable, other methods can be applied due to their popularity, which can make plaque control more acceptable. As there was a combination of single-tuft brushes with toothpicks, the effectiveness of the former on its own cannot be verified, though it may be suggested that their results corroborate those from the present study, since the use of toothpicks alone is generally regarded as inefficient.

In a randomized, single-blinded, controlled clinical trial ${ }^{10}$ performed with orthodontic patients, subjects wearing lingual fixed appliances were asked to brush with a triple head or an orthodontic toothbrush alone for one month. Subsequently, they were instructed to brush in conjunction with a single-tufted toothbrush for an additional month. Their teeth were professionally cleaned at baseline and one month later. Similarly to the present study, the authors observed a positive effect of the single-tuft brush: when used alone, the triple-headed toothbrush seemed to have removed dental biofilm more effectively than the orthodontic toothbrush. The addition of a single-tuft brush, however, eliminated differences between groups.

As far as the authors are aware, there have only been a few studies comparing single-tuft brushing with conventional brushing at the dentogingival areas. Caution must be taken with the interpretation of the results from this study, to prevent a hasty notion that single-tuft brushes should be indicated as a sole method for oral hygiene. The present study did not aim to directly influence clinicians into recommending STB as a substitute to conventional mechanical biofilm control methods. Additionally, Lee \& Moon ${ }^{26}$ reported that participants in their study complained that using single-tuft brushes was rather tiresome. Such drawbacks suggest that single-tuft brushes should be used as an additional tool and not as single method of oral hygiene. Some limitations of this study include the short-term nature of the collected data, making it difficult to forecast long-term results. In addition, the age of the volunteers varied from 18 to 30 years, with occasional differences in motivational levels and possible inherent differences in the anatomy of their dentition, which may, to some extent, interfere with the results. Longer follow-up studies should be performed to evaluate the longitudinal effects of the tested methods.

In general, this study was able to demonstrate the short-term effectiveness of single-tuft brushes, though it must be stressed that they should only be used as an adjuvant strategy to conventional brushing to tackle crevicular areas of buccal and lingual surfaces in the same way as dental flossing is combined to conventional brushing to tackle interdental areas.

In conclusion, the single-tuft brush tested in this study was effective at controlling short-term dental biofilm new formation at the dentogingival area.

\section{Acknowledgements}

The authors wish to acknowledge Bitufo - Hypermarcas for providing the materials tested in this study.

\section{References}

1. Loe $H$, Theilade $E$, Jensen SB. Experimental gingivitis in man. $J$ Periodontol. 1965 May-Jun;36:177-87.

2. Lang NP, Schätzle MA, Löe $H$. Gingivitis as a risk factor in periodontal disease. J Clin Periodontol. 2009 Jul;36 Suppl 10:3-8. doi: 10.1111/j.1600051X.2009.01415.x.

3. Peruzzo DC, Gimenes JH, Taiete T, Casarin RC, Feres M, Sallum EA, et al. Impact of smoking on experimental gingivitis. A clinical, microbiological and immunological prospective study. J Periodontal Res. 2016 Mar 3. doi: $10.1111 /$ jre.12363.

4. Arweiler NB, Henning G, Reich E, Netuschil L. Effect of an aminefluoride-triclosan mouthrinse on plaque regrowth and biofilm vitality. J Clin Periodontol. 2002 Apr;29(4):358-63.

5. Deacon SA, Glenny AM, Deery C, Robinson PG, Heanue M, Walmsley $A D$, et al. Different powered toothbrushes for plaque control and gingival health. Cochrane Database Syst Rev. 2010 Dec 8;(12):CD004971. doi: 10.1002/14651858.CD004971.pub2.

6. Van der Weijden FA, Slot DE. Efficacy of homecare regimens for mechanical plaque removal in managing gingivitis a meta review. J Clin Periodontol. 2015 Apr;42 Suppl 16:S77-91. doi: 10.1111/jcpe.12359.

7. Gomes LK, Sarmento CF, Seabra FR, Santos PB, Pinheiro FH. Randomized clinical controlled trial on the effectiveness of conventional and orthodontic manual toothbrushes. Braz Oral Res. 2012 JulAug;26(4):360-5.

8. Sharma S, Yeluri R, Jain AA, Munshi AK. Effect of toothbrush grip on plaque removal during manual toothbrushing in children. J Oral Sci. 2012;54(2):183-90.

9. Klukowska M, Grender JM, Conde E, Ccahuana-Vasquez RA, Ram Goyal C. A randomized clinical trial evaluating gingivitis and plaque reduction of an oscillating-rotating power brush with a new brush head with angled bristles versus a marketed sonic brush with self-adjusting technology. Am J Dent. 2014 Aug;27(4):179-84.

10. Ashkenazi M, Salem NF, Garon S, Levin L. Evaluation of Orthodontic and Triple-headed Toothbrushes When Used Alone or in Conjunction 
with Single-tufted Toothbrush in Patients with Fixed Lingual Orthodontic Appliances. A Randomized Clinical Trial. N Y State Dent J. 2015 Apr;81(3):31-7.

11. BergenholtzA, Brithon J. Plaque removal by dental floss or toothpicks. An intra-individual comparative study. J Clin Periodontol. 1980 Dec;7(6):51624.

12. Lindhe J, Karring T, Lang NP. [Clinical Periodontology and Implant Dentstry]. 5. ed. Rio de Janeiro (RJ): Guanabara Koogan; 2010. p.689. Portuguese.

13. Hujoel PP, Cunha-Cruz J, Banting DW, Loesche WJ. Dental flossing and interproximal caries: a systematic review. J Dent Res. 2006 Apr;85(4):298-305.

14. Bogren A, Teles RP, Torresyap G, Haffajee AD, Socransky SS, Wennström $\mathrm{JL}$. Clinical and microbiologic changes associated with the combined use of a powered toothbrush and a triclosan/copolymer dentifrice: a 3-year prospective study. J Periodontol. 2007 Sep;78(9):1708-17.

15. Ferraz C, Gomes CAS, Gomes R, Rached RSGA, Toleso BEC. [Mechanical control of bacterial plaque with conventional and single tuffed brushes]. Rev Assoc Paul de Cir Dent.1987;41(4):206-9. Portuguese.

16. Rapp GE, Toledo BEC, Neto CB, Abi Rached RSG. [Effect of the intracrevicular techniques by Bass and Unitufo with or without dental flossing on the interproximal gingiva: histomorphological analysis in humans]. Rev Odontol UNESP. 1997;26(2):325-36. Portuguese.

17. Franceschini $\mathrm{C}$, Oppermann RV. [Effect of the intracrevicular techniques by Bass and Unitufo with or without dental flossing on the interproximal gingiva: histomorphological analysis in humans]. Rev Bras Odontol 1987;44:2-7. Portuguese.

18. Erovic Ademovski S, Lingström P, Winkel E, Tangerman A, Persson $\mathrm{GR}$, Renvert S. Comparison of different treatment modalities for oral halitosis. Acta Odontol Scand. 2012 May;70(3):224-33. doi: 10.3109/00016357.2011.635601.

19. Ademovski SE, Persson GR, Winkel E, Tangerman A, Lingström P, Renvert $\mathrm{S}$. The short-term treatment effects on the microbiota at the dorsum of the tongue in intra-oral halitosis patients--a randomized clinical trial. Clin Oral Investig. 2013 Mar;17(2):463-73. doi: 10.1007/ s00784-012-0728-y.

20. Peruzzo DC, Jandiroba PF, Nogueira Filho Gda R. Use of $0.1 \%$ chlorine dioxide to inhibit the formation of morning volatile sulphur compounds (VSC). Braz Oral Res. 2007 Jan-Mar;21(1):70-4.

21. Sälzer S, Slot DE, Dörfer CE, Van der Weijden GA. Comparison of triclosan and stannous fluoride dentifrices on parameters of gingival inflammation and plaque scores: a systematic review and meta-analysis. Int J Dent Hyg. 2015 Feb;13(1):1-17. doi: 10.1111/idh.12072.

22. Ainamo J, Bay I. Problems and proposals for recording gingivitis and plaque. Int Dent J. 1975 Dec;25(4):229-35.

23. Re $D$, Augusti $G$, Battaglia $D$, Gianni $A B$, Augusti $D$. Is a new sonic toothbrush more effective in plaque removal than a manual toothbrush? Eur J Paediatr Dent. 2015 Mar;16(1):13-8.

24. Sharma NC, Qaqish J, Walters PA, Grender J, Biesbrock AR. A clinical evaluation of the plaque removal efficacy of five manual toothbrushes.
J Clin Dent. 2010;21(1):8-12.

25. Wilder RS, Bray KS. Improving periodontal outcomes: merging clinical and behavioral science. Periodontol 2000. 2016 Jun;71(1):65-81. doi: 10.1111/prd.12125.

26. Lee DW, Moon IS. The plaque-removing efficacy of a single-tufted brush on the lingual and buccal surfaces of the molars. J Periodontal Implant Sci. 2011 Jun;41(3):131-4. doi: 10.5051/jpis.2011.41.3.131.

27. Eberhard J, Grote K, Luchtefeld M, Heuer W, Schuett H, Divchev D, et al. Experimental gingivitis induces systemic inflammatory markers in young healthy individuals: a single-subject interventional study. PLoS One. 2013;8(2):e55265. doi: 10.1371/journal.pone.0055265.

28. Friedman MT, Barber PM, Mordan NJ, Newman HN. The "plaque-free zone" in health and disease: a scanning electron microscope study. J Periodontol. 1992 Nov;63(11):890-6.

29. Bergström J. Photogrammetric registration of dental plaque accumulation in vivo. Acta Odontol Scand. 1981;39(5):275-84

30. Quirynen $M$, van Steenberghe D. Is early plaque growth rate constant with time? J Clin Periodontol. 1989 May;16(5):278-83.

31. Maliska AN, Weidlich P, Gomes SC, Oppermann RV. Measuring early plaque formation clinically. Oral Health Prev Dent. 2006;4(4):273-8.

32. Branco P, Weidlich P, Oppermann RV, Rösing CK. Early supra- and subgingival plaque formation in experimental gingivitis in smokers and never-smokers. Oral Health Prev Dent. 2015;13(1):13-20. doi: 10.3290/j. ohpd.a32669.

33. Pretty IA, Edgar WM, Smith PW, Higham SM. Quantification of dental plaque in the research environment. J Dent. 2005 Mar;33(3):193-207.

34. Muniz FW, Sena KS, de Oliveira CC, Veríssimo DM, Carvalho RS, Martins RS. Efficacy of dental floss impregnated with chlorhexidine on reduction of supragingival biofilm: a randomized controlled trial. Int J Dent Hyg. 2015 May;13(2):117-24. doi: 10.1111/idh.12112.

35. Van Strydonck DA, Slot DE, Van der Velden U, Van der Weijden F. Effect of a chlorhexidine mouthrinse on plaque, gingival inflammation and staining in gingivitis patients: a systematic review. J Clin Periodontol. 2012 Nov;39(11):1042-55. doi: 10.1111/j.1600-051X.2012.01883.x.

36. Herrera D, Roldán S, Santacruz I, Santos S, Masdevall M, Sanz M. Differences in antimicrobial activity of four commercial $0.12 \%$ chlorhexidine mouthrinse formulations: an in vitro contact test and salivary bacterial counts study. J Clin Periodontol. 2003 Apr;30(4):307-14.

37. Papaioannou W, Vassilopoulos S, Vrotsos I, Margaritis V, Panis V. A comparison of a new alcohol-free $0.2 \%$ chlorhexidine oral rinse to an established $0.2 \%$ chlorhexidine rinse with alcohol for the control of dental plaque accumulation. Int J Dent Hyg. 2015 Oct 9. doi: 10.1111/idh.12182.

38. Segreto VA, Collins EM, Beigwanger BB, De la Rosa M, Issacs RL, Lang $\mathrm{NP}$, et al. A comparison of mouthrinses containing two concentrations of chlorhexidine. J Periodontol Res. 1986;21(suppl):23-32.

39. Arora V, Tangade P, T LR, Tirth A, Pal S, Tandon V. Efficacy of dental floss and chlorhexidine mouth rinse as an adjunct to toothbrushing in removing plaque and gingival inflammation - a three way cross over trial. J Clin Diagn Res. 2014 Oct;8(10):ZC01-4. doi: 10.7860/JCDR/2014/8807.4943. 